\title{
Eficiência Subnacional na Rio+C40
}

\section{Leonardo Mercher $^{1}$}

\section{RESUMO}

A atuação subnacional das cidades na Rio+C40 demonstrou eficiência diante de desafios ambientais comuns aos Estados na Rio+20, em 2012.

Palavras-chave: Paradiplomacia; Ambiente.

Cidades e governos locais, nos últimos trinta anos, buscaram se inserir nos principais debates e dinâmicas das relações internacionais contemporâneas. Com a pluralidade dos desafios econômicos, políticos e culturais reconhecidos na atualidade, prefeitos e demais representantes de governos locais tomaram para si a responsabilidade do diálogo e planejamento de políticas públicas que atendam às necessidades das sociedades às quais representam. 0 diálogo entre esses novos atores permite identificar um planejamento descentralizado dessas políticas, ou seja, a materialização de medidas públicas, por parte de governos locais, sem a participação direta de seus governos centrais (estatais).

Diversas cidades espalhadas pelo mundo participam de redes, organizações e grupos voltados à inserção do poder local nas relações internacionais. A cooperação descentralizada municipal, como materializada pelo grupo C40 de Grandes Cidades Para Liderança do Clima - fundado em 2005 - busca estabelecer um diálogo transnacional entre diversas autoridades locais e possibilitar soluções conjuntas para os mais diversos temas atualmente nas agendas internacionais. Ao ocorrer a Rio+20, evento cujo cerne é a questão ambiental na esfera político-internacional, as cidades membros do grupo C40 realizaram paralelamente, na cidade do Rio de Janeiro, um encontro oficial sobre a diminuição dos gases de efeito estufa: a Rio+C40. 
Esse encontro, realizado no Forte de Copacabana, reuniu diversas autoridades, bem como representantes das 59 cidades-membros $(C 40,2012)$, desde cidades consideradas globais (SASSEN, 2008) como Nova York, Buenos Aires, São Paulo e Rio de Janeiro, até cidades médias afiliadas ao grupo, como Curitiba e Lagos. Sob a presidência de Michael Bloomberg, a Rio $+\mathrm{C} 40$ apresentou experiências ambientais das cidades presentes, bem como estas se comprometeram com metas coletivas (globais) e individuais (municipais) que visavam, dentre outras obrigações, a alcançar a redução de 248 milhões de toneladas de gases do efeito estufa (GEE) até 2020 e 1,3 bilhão de toneladas de emissões coletivas de dióxido de carbono (CO2) até 2030 (C40, 2012).

Ainda que esse comprometimento seja por intermédio de uma carta de intenções, sua materialização, de forma paralela às negociações dos Estados na Rio+20, demonstrou maior eficiência das negociações subnacionais em relação às nacionais. 0 ex-presidente dos Estados Unidos, Bill Clinton, também participou do evento através de web-conferência e defendeu: "Se as cidades conseguirem mostrar que é possível reduzir as emissões, melhorando a qualidade de vida e a saúde pública no processo, mais cidades e nações terão o desejo de se comprometer e agir" (VASTAG, 2012). Segundo discurso do prefeito da cidade do Rio de Janeiro, Eduardo Paes: "a mensagem que os prefeitos querem passar é que uma série de decisões e ações já estão sendo tomadas e muitas outras ainda estão por vir" (VASTAG, 2012).

Em complemento a essa afirmação, Michael Bloomberg pediu aos governantes globais que dessem, às cidades, autoridade e poder para participarem, cada vez mais, do desenvolvimento sustentável e ressaltou: "Somos cidades que se uniram em torno de boas práticas. Não podemos só falar em mudanças, sem tomarmos uma atitude" (VASTAG, 2012). Segundo Alfredo Junqueira, “os representantes das cidades cobraram dos governos centrais de seus países mais apoio e autonomia para políticas públicas locais" (2012). Eles também reforçaram que "pretendem cumprir suas metas e estreitar seus laços mesmo que os chefes de Estado na Rio+20 não cheguem a um consenso" (JUNQUEIRA, 2012).

Dentro de seus discursos, bem como dos demais prefeitos e autoridades presentes, mais uma vez emerge o princípio da subsidiariedade, ao se defender a descentralização da ação política. Este princípio, que seria "a repartição de atribuições ou competências entre diversos âmbitos" (STUART, 2004, p.125), tão presente no 
desenvolvimento da atuação subnacional contemporânea, insere-se nos discursos e iniciativas das cidades na Rio+C40, materializado em sua Carta de Intenções. A Carta de Intenções Rio+C40 conseguiu, antes do final da Rio+20, responder positivamente ao desafio ambiental mundial de forma coletiva e descentralizada. Ao compreenderem a questão ambiental como de natureza transnacional, atingindo tanto nações como sociedades locais, independentemente de fronteiras políticas, as cidades presentes na Rio+C40 buscaram maior engajamento na questão que também as atinge.

Vale ressaltar também que o progresso nos debates da Rio+C40 deveu-se por serem, as cidades, consideradas "atores mistos" (SALOMON; NUNES, 2007, p.103), ou seja, livres de determinadas preocupações relacionadas às questões de soberania política presentes nos Estados - como segurança territorial. As cidades acabam por gozar de maior liberdade política internacional e de cooperação para firmar cartas e tratados, bem como instrumentalizar políticas públicas livres de grandes processos burocráticos como os nacionais. A ação estatal sobre o mesmo tema, a Rio+20, foi considerada pelas próprias cidades como "decepcionante" (PARADIPLOMACIA.ORG, 2012):

Pode-se observar que, dos elementos positivos em meio a tantas decepções, houve uma evolução substancial a respeito do lugar outorgado no debate das autoridades locais e regionais, bem como o avanço voluntário dessas mesmas autoridades com ações concretas diante das questões ambientais.

O progresso da Rio+C40 deveu-se, ainda, à iniciativa coletiva de "não esperar as decisões dos governos e chefes de estados para atuar" (PARADIPLOMACIA.ORG, 2012), tomando a frente de negociações paralelas e independentes das que ocorriam na Rio+20. No balanço geral da ação estatal na Rio+20, proferido pelas cidades na revista online Paradiplomacia.org, as críticas levantadas apontam para um possível descompromisso dos Estados com o desenvolvimento sustentável, sobretudo quando mudanças necessárias exigiriam alterações na sua estrutura econômica.

Pode-se dizer que a eficiência subnacional na Rio+C40 seria a somatória do princípio da subsidiariedade - maior liberdade política em relação aos entraves de soberania dos Estados, a responsabilidade política inerente em sanar os problemas de suas comunidades - as questões ambientais atingem a todos, a prática consolidada da cooperação descentralizada - materializada aqui na C40, e a constante busca desses atores em serem reconhecidos no cenário internacional como novas peças-chaves para 
as dinâmicas contemporâneas das relações internacionais. A Rio+C40 torna-se, então, um novo marco na atuação subnacional contemporânea permitindo identificar maior avanço em uma questão também discutida pelos governos centrais.

\section{Referências Bibliográficas}

C40, CITIES CLIMATE LEADERSHIP GROUP. Disponível em www.c40.org. Acesso em 08 de jul. de 2012.

JUNQUEIRA, Alfredo. Prefeitos do C40 acertam redução de gases poluentes. Disponível em www.estadão.com.br. Acesso em 19 de jun. de 2012.

PARADIPLOMACIA.ORG. Las autoridades locales y el balance de Río+20. Disponível em www.paradiplomacia.org. Acesso em 11 de jul. de 2012.

SALOMON, Mónica; NUNES, Carmen. A Ação Externa dos Governos Subnacionais no Brasil: Os Casos do Rio Grande do Sul e de Porto Alegre. Um Estudo Comparativo de Dois Tipos de Atores Mistos. Rio de Janeiro: Contexto Internacional, vol. 29, n. 1, p. 99-147, 2007.

SASSEN, Saskia; A.T. Kearney Global Management Consultants; The Chicago Council of Global Affairs. The 2008 Global Cities Index. Washington: Foreign Policy Magazine, vol. nov./dez., p. 68-76, 2008.

STUART, Ana Maria. Regionalismo e democracia: o surgimento da dimensão subnacional na União Europeia. In: VIGEVANI, Tullo et al. A dimensão subnacional e as Relações Internacionais. São Paulo: Educ/Unesp/EdUSC/FAPESP, 2004.

VASTAG, Ana Luiza. C40 na Rio+20: Prefeitos se comprometem a reduzir emissão de CO2. Disponível em http://viajeaqui.abril.com.br /materias/c40-na-rio20-prefeitos-secompr ometem-com-a-reducao-de-emissao-de-co2-noticias. Acesso em 10 de jul. de 2012. 